\title{
A Case of Schizophrenia with High Expressed Emotion, Caregivers Burnout and Family Dysfunction
}

\author{
Ms. Sabana Nasrin Islam ${ }^{1}$, Ms. Buli Nag Daimari ${ }^{2 *}$
}

\section{ABSTRACT}

Ongoing family stress and demands during the course of treatment and care giving pose challenges for the mental health professionals besides the primary care provided by the family. The present case illustration allows the practitioner/clinicians to see the full range of family relationships and how family members are impacted when one or more members are experiencing hurt and pain. Family relationships are sources of most intense emotions in people's lives and hearing the experiences and views of the entire family gives us a comprehensive assessment which helps the practitioner intervene at the level appropriate to the individuals need. The case highlights the importance of family interactional pattern in the management of Schizophrenia.

Keywords: Schizophrenia, Family stress, family relationships, Mental health professionals, Psychiatric Social Work intervention

\section{CASE INTRODUCTION:}

Mr. S.P. was a 23 year old unmarried male, studied up to $10^{\text {th }}$ standard, Hindu by religion from a middle socio-economic status and urban background. He was not engaged in any gainful employment as his illness started during the critical period of adolescence.

The case was referred for family intervention as there was a high level of expressed emotion seen with dysfunctional family functioning.

\section{BRIEF CLINICAL HISTORY:}

The patient was apparently alright 9 years back but then his symptoms started gradually with continuous course and deteriorating progress. The characteristic symptoms presented were decreased sleep, increased anger, threatening behaviour, suspiciousness towards family members, referential ideas. He was admitted in LGBRIMH for these symptoms. On medication he was maintaining well but every time he relapses because of his refusal to take medicines. He

\footnotetext{
${ }^{1}$ MSW, Mphil, and Psychiatric social worker, Department of Psychiatric Social Work, LGB Regional Institute of Mental Health, Assam, India.

${ }^{2}$ MSW, Mphil, Ph.D Scholar (TISS Mumbai), Psychiatric social worker \& Junior Consultant, Department of Psychiatric Social Work, LGB Regional Institute of Mental Health, Assam, India

*Corresponding Author

(C) 2015 I S Islam, B Daimari; licensee IJIP. This is an Open Access Research distributed under the terms of the Creative Commons Attribution License (http://creativecommons.org/licenses/by/2.0), which permits unrestricted use, distribution, and reproduction in any Medium, provided the original work is properly cited.
} 
was admitted in LGBRIMH for the third time because of the increase in the symptoms since the last 1 month. There is a positive family history of mental illness in both the paternal and maternal side. On MSE he was found to be having increased motor activity and ideas of reference towards family members. He was provisionally diagnosed as Schizophrenia (ICD-10 classification).

\section{SOCIAL MILIEU:}

Patient is the second among three siblings born out of non- consanguineous union. He hails from middle socio economic status of urban background from Guwahati. He lives in a nuclear family. The family do not interact much with the people in and around from before.

\section{FAMILY GENOGRAM:}

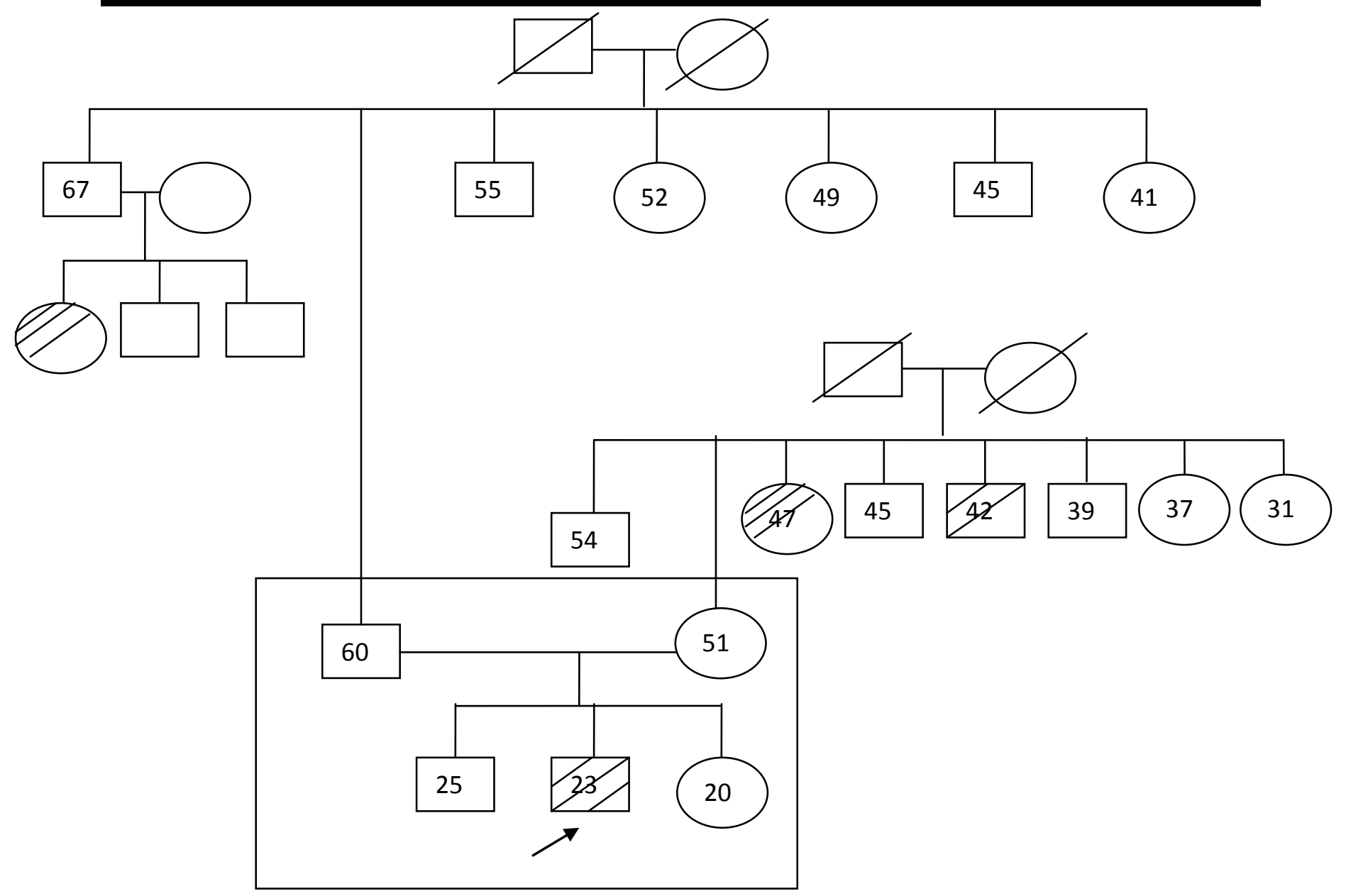

\section{FAMILY CONSTELLATION:}

Father: Patient's father is 60 years old, studied till Graduation and is a bank employee and only earning member in the family. He is short tempered and autocratic person by nature. He is also said to be conservative in outlook. His relationship with patient is need based.

Mother: Patient's mother is 51 years old, studied up to HS, she is a housewife. Patient's mother is extrovert by nature. She is overprotective of her children right from their childhood. She is available to her children all the time physically and emotionally. 
Brother: Patient's brother is 25 years old, he is persuading B.Com in Accountancy. He could not finish his studies age appropriately as he had numerous failures once in the $9^{\text {th }}$ standard, once in HSLC and twice during Graduation. At present his relationship with the patient is not appreciable.

Second is the index patient.

Sister: Patient's sister is 20 years old; she is persuading her Graduation in Arts stream. She is loving and caring by nature.

\section{FAMILY INTERACTION PATTERN:}

\section{Interaction between parents:}

Interaction between parents is poor as the mother feels that she is hardly heard of when matters relating to family issues and other daily hassles. As father was away from family because of his occupational demand, matters were hardly communicated to him in upbringing and rearing of children.

\section{Interaction between siblings:}

Interaction is found to be minimal among the siblings. They hardly share their daily experiences to each other. They express their anger and disagreement through shouting, fighting and other physical means where sister is asked not to get involved in such behaviour as she is a women which society does not approve.

\section{Interaction between parent-child}

Relationship between parent and child is not enjoyable and rewarding. No positive interaction is present among the members of the family in terms of spending time together, leisure activities and other social visits.

\section{FAMILY DYNAMICS:}

\section{Boundary and subsystem:}

Boundary of the present existing family was found to be closed and rigid as it prevents the individual members from having meaningful contact with each other. External boundary also was closed and rigid as each member of the family was restricted from sharing anything with close relatives, friends and neighbours.

\section{Family Developmental stage:}

Family is presently in the families launching young adults' stage.

\section{Leadership and decision making:}

In the decision making process authoritarian decision making was found from the father's side as he believes that his wife is not competent enough to take any decisions in the family. Sometimes, for any major decisions, discussions are made with wife though much of the suggestions are not taken into account. Patient's father is the nominal and functional leader of the family. Mother and siblings helps in implementing the decisions taken by the father. 


\section{Role structure and functioning:}

Father is able to take the responsibily of rearing children in giving instrumental support like education, food and other basic necessities for his family. His emotional involvement with wife and children is not satisfactory, unlike the mother who plays an expressive role in the family. Complementary roles are hardly played by the family members.

\section{Communication:}

Verbal and non- verbal communication was present in the family. Switchboard communication is seen in between the father and the children since childhood.

\section{Reinforcement:}

Positive reinforcement like verbal appraisal, encouragement is present from mother at times. Father hardly gives any reinforcement to children. However critical and sarcastic comments are passed on by the father to mother and children for their mistakes and inefficiency.

\section{Cohesiveness:}

The family seems to be lacking emotional involvement for the other members in the family. They hardly celebrate any rituals either at home or outside the family.

\section{Adaptive pattern:}

Poor problem solving ability and coping strategy was found to be present in the family. Father used to escape from situation whenever there is problem in family owing to patient's behaviour.

\section{Primary support:}

Primary support from family members can be said to be adequate in terms of financial matters but not in terms of emotional support.

\section{Secondary support:}

The family has reduced their social network with people for fear of being criticized and discriminated by others. Secondary support from relatives, friends and neighbors is inadequate as they have reduced their contact apprehending the patient's behaviour as well as they do not feel comfortable in asking for help from any relatives and friends.

\section{Tertiary support:}

Tertiary support is also adequate as all the basic facilities required i.e. hospitals; Government agencies and religious institutions are there in his locality.

\section{Burden:}

Care burden is present.

\section{Social status of the family:}

The patient lives in a pucca house, which has got four rooms and a kitchen, with an attached bathroom. They have got a lawn in front of their house. Moreover, the house is properly ventilated. The sole earner is the father of the patient only.

\section{PERSONAL HISTORY:}

\section{Birth order: Patient is the second amongst three siblings}

Developmental milestones: The developmental milestones were age appropriate.

Health complications in childhood: In childhood, the patient did not have any marked health complications. 
Behaviour during childhood: Patient as a child was very much demanding in childhood and whatever he required needs to be given immediately, otherwise he would trouble the other members of the house. The patient's father used to give into his demands very often even if the mother did not want to. So there would arise difference in the opinions.

Educational History: At the age of 6, patient for the first time went to school. He continued his schooling in the same school till $9^{\text {th }}$ standard and then after he reached $10^{\text {th }}$ standard, he did appear for his exams as his illness started following which he discontinued his studies. He was an average student in school and he adjusted well with his peers.

Occupation: Patient is not engaged in any productive work.

Marital History: Patient is unmarried.

Temperamental History: Temperamentally, patient was a difficult child. He was irritable in nature and was preoccupied in his own world. He had very minimal contact with others. He was not expressive and lacked the skills to communicate his needs and feelings. He was however interested in listening music and watching television.

\section{SOCIAL ANALYSIS AND DIAGNOSIS:}

The index patient educated upto $10^{\text {th }}$ standard, aged 23 years old, unmarried, Hindu, hailing from middle socio- economic background from Guwahati.

Social analysis reveals that the patient had predisposition to illness because of positive family history. The family has never had open and clear interactions and communications. The interaction in the family members is most characterized by outward expression of anger and a sense of lack of 'we' feeling exists. Father has been an authoritarian and there has been autocratic decision making in the family. Father's short tempered, critical and domineering nature has set as role model for the patient. Though medications were continued by the patient with a good understanding about the illness, still high amount of criticality seemed to be there from the family and this may be because they are stressed out or over burdened in looking after him. These expressed emotions of criticality and hostility were major maintaining factors of the patient's illness. Patient was described to be difficult child with behavioral and emotional problems from early childhood which may be explained because of lack of emotional responsiveness from the parents. Also, because patient cannot communicate his needs, interest and feelings directly with healthy communication lacking between family members his emotional development is disturbed which leads to unhealthy emotional adjustment to others. The families lack of social support from relatives and friends may have led to the increase in family burden besides, non acceptance of the family by the relatives. Also, role strain is found to be high on the mother because of absence of complementary roles in the family. The burden of caregiving has fallen on the mother exploiting the traditional caring role and persisting inequalities between the male and female stereotype. Maladaptive coping strategies especially in father has led to the maintenance of patient's behavior. 
Points from Social Analysis:

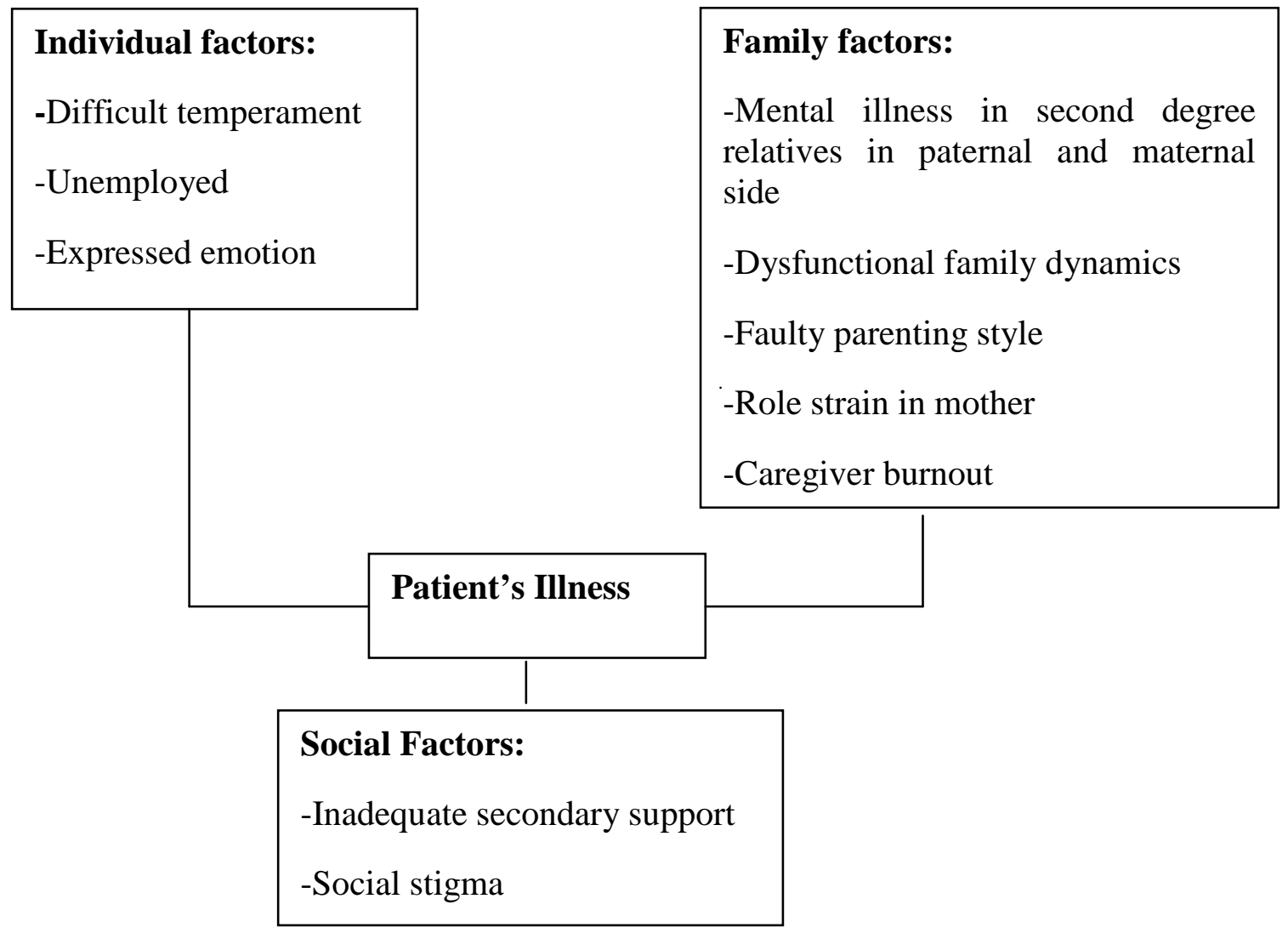

\section{PSYCHO SOCIAL MANAGEMENT PLAN:}

At the family level:

Objectives:

a) To provide Psycho education to the family members

b) To address the issues related to the high amount of stress in the family

\section{Management strategies:}

Supportive Counselling

Family psychoeducation

Addressing care-giver's burden

Handling reactions

Problem solving strategies

\section{Family session- 6}

\section{Course of the therapy:}

The family was referred for psycho social assessment and family intervention. The session started with building rapport with the family having an empathic understanding of their concerns and the prolonged crisis the family is going through over the past years. The family was increasingly feeling the strain and has reached a stage of collapse of care and giving support to the patient. The worker validated families coping with the chronic condition at the same time 
tried to explore the areas as how the patient has been treated by the family over the years. An assessment into the family dynamics giving a supportive stance to the family was done during the interview session. The worker used three tools to validate the information collected during the interview.

Life distress Inventory- This scale was used in order to check the distress of the members, significant amount of distress was found in areas of management, education, with regard to social life, personal independence, expectation for future.

General Functioning Scale- The findings suggest that there is problem in the dimension of problem solving, communication, roles.

Family Burden Scale- The findings suggestive of marked level of stress in areas of disruption of routine family activities, disruption of leisure especially in case of the mother, disruption of family interaction and also with regard to future prospects.

\section{Supportive Counseling with family}

The aim was to provide an accepting environment by allowing the family to ventilate their emotions and feelings. The therapist validated their emotions, empathetically listened to their current concerns and provided reassurance to them. They were helped to reflect on their understanding about the behaviors and symptoms of the patient and encouraged to have positive involvement with the patient.

\section{Handling reactions:}

As the patient has grown up and his behavioral responses are not acceptable to the larger society, family has decreased their social life activities in terms of visits to social places, outings, and social events such as marriage and other ceremonies. In addition, there is also decrease in the number of visits to relatives and friends and visits by the relatives and friends to the family. This has resulted as a feeling of shame, social embarrassment and fear of stigma. The family was helped in accepting the reality and reassured that something can be done to improve, sustain or keep going as long as possible the quality of life of the patient and the family. The worker believes that until positives have been recognized and are being acted upon, acceptance cannot be fully reached. Reflecting on the attitudes of the family towards the patient the worker was able to bring changes in their outlook of handling the patient. The worker, at the same time empathized with the parents given the nature of the problem but at the same time it was told that much of the decrease in social life can be effectively reversed. Parents were advised to visit to places which have a high degree of social approval like temples and other religious institutions. They were also suggested to build relationships and network with other close kins where they feel accepted.

\section{Psycho education:}

Apart from acknowledging their feelings, what was needed at present was solid information about how to move forward with such a chronic condition of the patient. The worker explained 
about what the diagnosis means, the symptomatology, the possible course of the condition and the possible prognosis. Some of the possible options for the future and an understanding about the part the different personnels play and operates in a team were told to them.

Patient's family though had knowledge about patients illness they were still critical and hostile towards him. It was explained how such emotions can be triggering factors for the patient's illness. Their expectations were addressed and suggested that they should reduce their expectations to some extent and be supportive with whatever amount he was able to be productive. An insight into the patient's behavior was also given and importance of family support, their involvement was explained.

\section{Problem solving strategies:}

The family has a constant source of worry as how to manage their mentally ill person. The worker helped families with their management strategies involving two broad areas-the management of relations with the ill person and the family management of their own lives. The worker explained that while coping with positive symptoms can be hard they are clearly illness related and in that sense are forgivable. With negative symptoms, the initiatives has to come from the family to involve the patient which may take sustained effort to keep an initiative going specially, when there is little in the way of response of the patient. They were explained that there must be sufficient consistency between the various members of the family as anything else would confuse the patient. The family was explained that they should reduce their guilt feeling when legitimate means are considered to control any violent behaviour of the patient. To help families live there own life in the way they would choose as continuing carers, the worker helped the family giving professional support from the team, providing practical services like respite care or any other alternating care so as to provide a break from the onus of caring thus giving the family a chance to preserve a life of their own. The family was given assurance of receiving practical support from the hospital as and when necessary. Besides, the burden of care giving was addressed explaining the role structure and functioning of each of the family members. The worker also helped the family to look for developing relationship with other people facing the same difficulties.

\section{OUTCOME:}

The psychiatric social work intervention was effective in reducing the level of distress in the family. The attitude of the family was changed to the acceptance of illness. Besides, caregiver burnout was reduced to an extent by developing coping and problem solving skills in the family.

\section{FUTURE PLAN:}

The psychiatric social worker has plans to work at an individual level with the objective of engaging patient in structured activity and provide vocational counseling and rehabilitation. 


\section{LIMITATION:}

The psychiatric social worker could not intervene the patient as he was in the acute phase of symptoms. Conjoint interview sessions with both the parents and the patient were not possible during the stay in the hospital.

\section{CONCLUSION:}

The understanding of the family relationship and its context to the development and maintenance of psychological symptoms of patient should be a focus for any psychiatric social work intervention. It is recommended that mental health professionals give attention to the diverse family's reactions and behavioral management in dealing with a person with mental illness.

\section{REFERENCES:}

Barbara Thomlison(2010). Family Assessment Handbook; An introduction and practical guide to family assessment. $3^{\text {rd }}$ Edition. Brooks/Cole USA

Lewis R. Wolberg (1995). The techniques of Psychotherapy. $4^{\text {th }}$ edition. Jason Aronson Inc. London

Mathew Varghese, Anisha Shah, and GS Udaya Kumar, Family Intervention and Support in Schizophrenia: A manual on Family intervention for the Mental Health Professional, NIMHANS, Bangalore

Reading Material for the certificate course in Family Therapy (2001), Family psychiatry Centre, NIMHANS, Bangalore

Robert Paul Liberman (1988). Psychiatric Rehabilitation of chronic mental patients. American Psychiatric Press, Inc.

The ICD-10 Classification of Mental and Behavioral Disorders- Clinical Descriptions and Diagnostic guidelines (2007), A.I.T.B.S. Publishers, Delhi 